\title{
A Detection and Therapeutic Device to Overcome Sleep Apnea in Infants ${ }^{\dagger}$
}

\author{
T. Sudhakar ${ }^{1}$, Sindhiya R. ${ }^{1}$, Rimisha Gupta ${ }^{1}$, Sindu Divakaran ${ }^{1, *}$ \\ 1 Department of Biomedical Engineering, School of Bio and Chemical Engineering, Sathyabama Institute of Science and \\ Technology, Chennai \\ * Correspondence: sindudiva@gmail.com; \\ $\dagger$ Presented at International Conference on Bioengineering for Health and Environment (ICBHE 2020)
}

Received: 5.07.2020; Revised: 10.07.2020; Accepted: 12.07.2020; Published: 15.07.2020

\begin{abstract}
Among the various sleep-disordered breathing patterns infant's experience, like periodic breathing, premature apnea, obstructive sleep apnea, has been considered a major cause of concern. Upper airway structure, mechanics of the pulmonary system, etc., are a few reasons why the infants are vulnerable to obstructive sleep-disordered. An imbalance in the viscoelastic properties of the pharynx, dilators, and pressure can lead to airway collapse. A low level of oxygen in blood or hypoxemia is considered a characteristic in infants with severe OSA. Invasive treatments like nasopharyngeal tubes, continuous positive airway pressure (CPAP), or tracheostomy are found to be helpful in most cases where infants experience sleep apnea. This paper proposes an efficient system for monitoring obstructive sleep apnea in infants on a long-term basis, and if any anomaly is detected, the device provides Continuous Airway Pressure therapy until the abnormality is normalized.
\end{abstract}

Keywords: Apnea; CAP; OSA; Oxygen.

(C) 2020 by the authors. This article is an open-access article distributed under the terms and conditions of the Creative Commons Attribution (CC BY) license (https://creativecommons.org/licenses/by/4.0/).

\section{Funding}

This research received no external funding.

\section{Acknowledgments}

This research has no acknowledgment.

\section{Conflicts of Interest}

The authors declare no conflict of interest. 